\title{
Energy transmission in mechanically ventilated children: a translational study
}

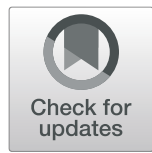

\author{
Martin C. J. Kneyber ${ }^{1,2^{*}}$ (D), Stavroula llia ${ }^{1,3}$, Alette A. Koopman ${ }^{1}$, Patrick van Schelven ${ }^{1}$, Jefta van Dijk1, \\ Johannes G. M. Burgerhof ${ }^{4}$, Dick G. Markhorst ${ }^{5}$ and Robert G. T. Blokpoel ${ }^{1}$
}

\begin{abstract}
Background: Recurrent delivery of tidal mechanical energy (ME) inflicts ventilator-induced lung injury (VILI) when stress and strain exceed the limits of tissue tolerance. Mechanical power (MP) is the mathematical description of the ME delivered to the respiratory system over time. It is unknown how ME relates to underlying lung pathology and outcome in mechanically ventilated children. We therefore tested the hypothesis that ME per breath with tidal volume $(\mathrm{Vt})$ normalized to bodyweight correlates with underlying lung pathology and to study the effect of resistance on the ME dissipated to the lung.

Methods: We analyzed routinely collected demographic, physiological, and laboratory data from deeply sedated and/or paralyzed children $<18$ years with and without lung injury. Patients were stratified into respiratory system mechanic subgroups according to the Pediatric Mechanical Ventilation Consensus Conference (PEMVECC) definition. The association between MP, ME, lung pathology, and duration of mechanical ventilation as a primary outcome measure was analyzed adjusting for confounding variables and effect modifiers. The effect of endotracheal tube diameter (ETT) and airway resistance on energy dissipation to the lung was analyzed in a bench model with different lung compliance settings.

Results: Data of 312 patients with a median age of 7.8 (1.7-44.2) months was analyzed. Age $(p<0.001)$, RR $p<0.001)$, and $\mathrm{Vt}<0.001$ ) were independently associated with MPrs. ME but not MP correlated significantly $(p<0.001)$ better with lung pathology. Competing risk regression analysis adjusting for PRISM III $24 \mathrm{~h}$ score and PEMVECC stratification showed that ME on day 1 or day 2 of MV but not MP was independently associated with the duration of mechanical ventilation. About $33 \%$ of all energy generated by the ventilator was transferred to the lung and highly dependent on lung compliance and airway resistance but not on endotracheal tube size (ETT) during pressure control (PC) ventilation.

(Continued on next page)
\end{abstract}

\footnotetext{
* Correspondence: m.c.j.kneyber@umcg.nl

${ }^{1}$ Division of Paediatric Critical Care Medicine, Department of Paediatrics, Beatrix Children's Hospital, University Medical Center Groningen, The University of Groningen, Internal Postal Code CA 80, P.O. Box 30.001, 9700, RB, Groningen, the Netherlands

${ }^{2}$ Critical Care, Anesthesia, Peri-operative Medicine \& Emergency Medicine (CAPE), The University of Groningen, Groningen, the Netherlands Full list of author information is available at the end of the article
}

(c) The Author(s). 2020 Open Access This article is licensed under a Creative Commons Attribution 4.0 International License, which permits use, sharing, adaptation, distribution and reproduction in any medium or format, as long as you give appropriate credit to the original author(s) and the source, provide a link to the Creative Commons licence, and indicate if changes were made. The images or other third party material in this article are included in the article's Creative Commons licence, unless indicated otherwise in a credit line to the material. If material is not included in the article's Creative Commons licence and your intended use is not permitted by statutory regulation or exceeds the permitted use, you will need to obtain permission directly from the copyright holder. To view a copy of this licence, visit http://creativecommons.org/licenses/by/4.0/ The Creative Commons Public Domain Dedication waiver (http://creativecommons.org/publicdomain/zero/1.0/) applies to the data made available in this article, unless otherwise stated in a credit line to the data. 
(Continued from previous page)

Conclusions: ME better related to underlying lung pathology and patient outcome than MP. The delivery of generated energy to the lung was not dependent on ETT size during PC ventilation. Further studies are needed to identify injurious MErs thresholds in ventilated children.

Keywords: Mechanical power, Energy per breath, Mechanical ventilation, Pediatric, Ventilator-induced lung injury $(\mathrm{VILI})$

\section{Background}

Mechanical ventilation (MV) as life-saving intervention is ubiquitous in pediatric intensive care units (PICU) but may simultaneously lead to ventilator-induced lung injury (VILI) [1]. Experimental and clinical studies have identified factors contributing to VILI to include volutrauma (i.e., delivery of large tidal volumes (Vt) as a surrogate for lung strain), lung stress, and atelectrauma (i.e., the repetitive opening and closure of alveoli) albeit that their exact role in the pediatric setting is not well understood [1, 2].

Mechanical power (MPrs) has been proposed as a measure and potential driver of VILI [3]. MPrs is the energy per breathing cycle multiplied by ventilation frequency [4]. It can be calculated during volumecontrolled (VC) ventilation using the respiratory rate (RR), peak inspiratory pressure (PIP), plateau pressure (Pplat), and positive end-expiratory pressure (PEEP) [5]. Although MPrs has been associated with mortality in ARDS patients, it is not well-established if MPrs should be normalized to lung volume or predicted bodyweight and how much power is delivered to the lung $[3,6-8]$.

It has not been studied how the conceptual framework of power translates to mechanically ventilated children. Obviously, two key components of MPrs (i.e., Vt and RR) are age-dependent (i.e., the older the child, the larger the $\mathrm{Vt}$ and the lower the RR), making those injurious thresholds for MPrs not uniform across the entire pediatric spectrum. Furthermore, pediatric critical care practitioners predominantly use a pressure-controlled (PC) mode of ventilation whereas the concept MPrs is based on VC ventilation although Becher et al. have proposed an approach to measure MPrs during PC ventilation using peak inspiratory pressure (PIP) instead of Pplat [9-11]. It needs to be studied if these modifications can be used to study mechanical power in children. Aside from these methodological aspects, infants and young children are generally ventilated with small endotracheal tube (ETT) sizes with high gas flow and high ventilation rate, all contributing to resistance (Rrs) [12]. Added to that, especially young children often suffer from disease conditions characterized by increased airway resistance such as viral bronchiolitis or pneumonia
[13]. It is thus unclear how much of the power is delivered to the lungs and how much is dissipated in the native airways.

We therefore sought to explore how MPrs and energy with Vt normalized to bodyweight (thereby eliminating age dependency) correlated with underlying lung pathology and patient outcome. In addition, we wanted to study if ETT size impacted energy delivery to the lung.

\section{Methods}

We analyzed routinely collected demographic, physiological, and laboratory data from deeply sedated and/or paralyzed children $<18$ years with and without lung injury on weekdays at 8 am during the first 3 days of MV. Data from patients with obstructive airway disease, documented chronic lung disease, neuromuscular disorders, premature birth with age corrected for postconceptional age less than 40 weeks, severe traumatic brain injury (i.e., Glasgow Coma Scale $<8$ ), chronic lung disease (i.e., tracheostomy ventilation), and severe pulmonary hypertension, managed with high-frequency oscillation ventilation or with an ETT leakage $>18 \%$ were excluded. The severity of the disease was assessed by the 24-h Pediatric Risk of Mortality II (PRISM II) [14]. Patients were stratified according to underlying respiratory system mechanics subgroups proposed by the Pediatric Mechanical Ventilation Consensus Conference (PEMV ECC) definition and pediatric acute lung injury consensus conference (PALICC) definition for PARDS [13, 15]. The Institutional Review Board approved the study and waived the need for informed consent. A bench study was performed to study how the ETT affected energy transmission to the lung (see Additional file 1).

Patients were ventilated in a $\mathrm{PC}$ ventilation mode, limiting inspiratory pressures $<28-32 \mathrm{cmH}_{2} \mathrm{O}$ and expiratory Vt (Vt-exp) $5-7 \mathrm{~mL} / \mathrm{kg}$ actual bodyweight (as there was no obesity in the patient cohort). Vt-exp was measured near the Y-piece in children $<10 \mathrm{~kg}$ (VarFlex $^{\mathrm{Tm}}$, Vyaire, Mettawa, Ill, USA). Mandatory breath rate setting was guided by the underlying pathology and age; the flow-time scalar is carefully monitored to identify appropriate inspiratory time setting and to avoid the development of intrinsic PEEP. The $\mathrm{I}$ to $\mathrm{E}$ ratio is not fixed. Initial PEEP was $4-6 \mathrm{~cm} \mathrm{H}_{2} \mathrm{O}$ and further titrated 
at the discretion of the attending physician, targeting $\mathrm{SpO}_{2} 88-92 \%$ for patients with lung injury. Unless dictated otherwise, the target $\mathrm{pH}$ was $>7.20$.

Demographic, physiological, and laboratory data were manually extracted from the patient's medical record. Ventilator settings and parameters were read from the ventilator. Plateau pressure (Pplat) and quasi-static compliance $(\mathrm{Crs})$ were measured at end-inspiration by a manual inspiratory hold maneuver of $3 \mathrm{~s}$. Metrics for oxygenation included the oxygenation index [OI] ([mean airway pressure $\left.\times \mathrm{FiO}_{2} \times 100\right] / \mathrm{PaO}_{2}$ ) and if the $\mathrm{SpO}_{2}$ was $<98 \%$ the oxygen saturation index [OSI] [mean airway pressure $\left.\times \mathrm{FiO}_{2} \times 100\right] / \mathrm{SpO}_{2}$ ). We calculated ventilatorfree days (VFD) through day 28, defined as the number of days within 28 days that a subject is alive and free of MV [16]. Patients were assigned 0 VFD if they remained intubated or died prior to day 28 without remaining extubated for more than $24 \mathrm{~h}$. MPrs was calculated as previously described [5]. The mechanical energy of the respiratory (MErs) was calculated by $0.098 \times\left(\mathrm{Vt} \times \mathrm{kg}^{-1}\right) \times(\mathrm{PIP}-[($ Pplat $-\mathrm{PEEP}) / 2])$.

\section{Statistical analysis}

The normality of data was assessed using the Kolmogorov-Smirnov test. Continuous data are presented as median and 25-75 interquartile range (IQR) and analyzed using the Mann-Whitney $U$ test (for comparing two groups) or Kruskal-Wallis test; Spearman correlation coefficient $\left(r_{s}\right)$ was calculated to analyze correlations. The $\chi^{2}$ test with Yates continuity correction was used to analyze categorical data. The primary outcome measure was the duration of mechanical ventilation (MV). Competing risk regression analysis (Fine and Gray model) was used to identify independent contributors to the duration of MV with death as a competing risk [17]. All statistical analyses were performed using software IBM SPSS, v24.0 (IBM Corp., Chicago, III, USA) with $P<0.05$ considered statistically significant.

\section{Results \\ Correlation MPrs and MErs with underlying lung pathology and patient outcome}

Data of 312 patients with a median age of $7.8(1.7-44.2)$ months was analyzed (Table 1). Of these, 186 patients $(61.5 \%)$ were younger than 12 months of age. Primary admission diagnosis was respiratory failure in 102 (32.7\%) and cardiac (including post-cardiac surgery) in $81(26.0 \%)$ patients. Sixty-nine (22.1\%) patients met PEMVECC criteria for restrictive and 78 (25.0\%) for mixed lung disease, and $7.7 \%$ of patients met PALICC criteria for PARDS. The duration of MV was 93 (44163) hours. Thirteen (4.2\%) patients died. Patients were ventilated for a median of $17.3 \mathrm{~h}(11.6-21.2)$ before the first measurement on day 1 was made.
Data on MPrs was available on the first day of MV for all patients, on day 2 for 169 (53.9\%), and on day 3 for $96(30.0 \%)$ patients. We found a direct relationship between age and MPrs $\left(r_{s}\right.$ 0.814, $\left.p<0.001\right)$. Vt-exp $\left(r_{s}\right.$ $0.112, p<0.01)$, weight $\left(r_{s} 0.837, p<0.001\right)$, and RR $\left(r_{s}\right.$ $-0.459, p<0.001$ ) were also significantly correlated with MPrs. There was also a significant correlation between MPrs and oxygen saturation index (OSI) ( $r_{s}$ 0.189, $p<0.001$ ) but not with oxygenation index (OI) or $\mathrm{PaO}_{2} /$ $\mathrm{FiO}_{2}$ ratio. PEEP was significantly correlated with MPrs $\left(r_{s} 0.311, p<0.001\right)$.

The distribution of MPrs on day 1 was significantly different $(p<0.001)$ across the cohort after stratification by PEMVECC criteria (Fig. 1). Linear regression analysis showed that age in months $(\beta-0.012[95 \% \mathrm{CI}-0.018-$ $-0.007, p<0.001$ ), RR ( $\beta 0.047$ [95\%CI 0.034-0.060, $p<0.001$ ), and total Vt (i.e., not normalized to bodyweight) ( $\beta 10.028$ [95\%CI 0.024-0.031, $p<0.001$ ) were independently associated with MPrs.

Next, we analyzed the mechanical energy per breath (MErs) [expressed as $\mathrm{mJ} / \mathrm{kg}$ ] after normalizing $\mathrm{Vt}$ to actual bodyweight. For the whole cohort, MErs was 10.2 (8.212.2) $\mathrm{mJ} / \mathrm{kg}$. MErs was not significantly correlated with age in months. There was a significant correlation between MErs and OI (rs 0.412, $p<0.001$ ), OSI ( $r s$ $0.438, p<0.001$ ), and $\mathrm{PaO}_{2} / \mathrm{FiO}_{2}$ ratio ( $r s-0.263$, $p<0.001)$. The distribution of MErs was significantly different $(p<0.001)$ across the cohort after stratification by PEMVECC criteria (Fig. 1b). MErs was 9.7 $\mathrm{mJ} / \mathrm{kg}(8.0-12.3)$ in patients with normal lung mechanics, $10.7 \mathrm{~mJ} / \mathrm{kg}(8.6-12.5)$ in patients with the restrictive disease, and $10.6 \mathrm{~mJ} / \mathrm{kg}(8.6-12.5)$ in patients with mixed disease although this difference did not reach statistical significance. MErs but not MPrs was significantly higher in non-survivors (11.7 [8.9-15.4] vs $10.1 \mathrm{~m} / \mathrm{kg}$ [8.2-12.1], $p=0.016$ ).

Patients with new PARDS during the first 3 days of MV had significantly higher MPrs (3.2 [1.7-8.3] vs 2.4 [1.5-3.7] J/L, $p=0.003)$ and MErs $(11.1 \mathrm{~mJ} / \mathrm{kg}$ [9.6-14.0] vs 10.0 [8.2-12.0], $p=0.001$ ) than those without PARDS. Analysis of patients with PARDS showed that MPrs or MErs was not significantly correlated with VFD-28 or different between survivor and non-survivors.

Univariate analysis showed that for the entire cohort only MErs was significantly correlated with VFD $\left(r_{s}-0.243, p<0.001\right)$. After stratification by age, we found a significant correlation between MPrs, MErs, and VFD in two age categories $(0-12$ months and 15 years) but not in children $>5$ years. Competing risk regression analysis adjusting for PRISM III $24 \mathrm{~h}$ score, age (in months), and PEMVECC stratification showed that MPrs on day 1 or day 2 of MV was not independently associated with VFD, whereas MErs on day 1 or day 2 was $(p<0.001)$. 
Table 1 Characteristics of the study population of $N=312$ mechanically ventilated children. Data are presented as median (25-75 interquartile range) or percentage (\%) of total. Ventilator-free days (VFD) through day 28 were defined as the number of days within 28 days that a patient was alive and free of mechanical ventilation [16]. Patients were assigned 0 VFD if they remained intubated or died prior to day 28 without remaining extubated for more than $24 \mathrm{~h}$. ${ }^{*}$ Denotes $p<0.005$ (Kruskal Wallis test). PRISM Pediatric Risk of Mortality; Ol oxygenation index

\begin{tabular}{|c|c|c|c|c|}
\hline & \multicolumn{4}{|c|}{ Patient stratification by Pediatric Mechanical Ventilation Consensus Conference category } \\
\hline & $\begin{array}{l}\text { Normal respiratory } \\
\text { system mechanics }\end{array}$ & $\begin{array}{l}\text { Restrictive respiratory } \\
\text { system mechanics } \\
\text { (i.e., reduced compliance) }\end{array}$ & $\begin{array}{l}\text { Mixed respiratory } \\
\text { system mechanics } \\
\text { (i.e., reduced } \\
\text { compliance and } \\
\text { increased resistance) }\end{array}$ & $\begin{array}{l}\text { Cardiac } \\
\text { (combination of } \\
\text { normal and altered } \\
\text { respiratory system } \\
\text { mechanics) }\end{array}$ \\
\hline & $N=84$ & $N=69$ & $N=78$ & $N=81$ \\
\hline \multicolumn{5}{|l|}{ Baseline patient characteristics } \\
\hline Age (months) * & $49.3(9.4-122.0)$ & $23.1(8.0-46.0)$ & $2.0(1.2-8.5)$ & $2.2(0.5-6.7)$ \\
\hline$\leq 12$ months (\%) & 29.78 & 39.1 & 84.6 & 84.0 \\
\hline 13-60 months (\%) & 20.2 & 34.8 & 11.5 & 6.2 \\
\hline$>60$ months (\%) & 50.0 & 26.1 & 3.8 & 9.9 \\
\hline Male gender (\%) & 61.9 & 58.0 & 62.8 & 63.0 \\
\hline Weight $(\mathrm{kg}) *$ & $16.5(8.0-29.5)$ & $12.4(8.5-17.5)$ & $5.0(4.0-6.7)$ & $4.2(3.6-6.9)$ \\
\hline PRISM III 24 h score & $8.5(5.0-14.0)$ & $10.0(6.0-15.0)$ & $11.0(8.0-15.0)$ & $12.0(7.0-15.5)$ \\
\hline PARDS (\%) & 0.0 & 5.8 & 24.4 & 1.2 \\
\hline Cstat $\left(\mathrm{cmH}_{2} \mathrm{O} / \mathrm{L} / \mathrm{kg}\right)^{*}$ & $0.59(0.43-0.78)$ & $0.55(0.39-0.73)$ & $0.34(0.28-0.44)$ & $0.5(0.32-0.6)$ \\
\hline \multicolumn{5}{|l|}{ Baseline ventilator settings } \\
\hline $\mathrm{PIP}\left(\mathrm{cmH}_{2} \mathrm{O}\right) *$ & $18(16-22)$ & $20(17-23)$ & $27(24-29)$ & $20(18-23)$ \\
\hline Pplat $\left(\mathrm{cmH}_{2} \mathrm{O}\right) *$ & $16(14-19)$ & $17(15-21)$ & $24(21-26)$ & $18(16-21)$ \\
\hline $\operatorname{PEEP}\left(\mathrm{cmH}_{2} \mathrm{O}\right) *$ & $5(5-6)$ & $5(5-6)$ & $6(5-7)$ & $5(5-6)$ \\
\hline$V t-\exp (\mathrm{mL} / \mathrm{kg}) *$ & $7.6(6.6-8.6)$ & $7.6(6.5-8.5)$ & $6.6(6.1-7.7)$ & $7.5(6.8-8.3)$ \\
\hline Inspiratory time $(s) *$ & $0.75(0.62-0.9)$ & $0.7(0.6-0.75)$ & $0.55(0.5-0.6)$ & $0.55(0.5-0.6)$ \\
\hline Mandatory breath rate $(/ \mathrm{min}) *$ & $22(17-30)$ & $23(20-30)$ & $40(32-40)$ & $35(29-40)$ \\
\hline \multicolumn{5}{|l|}{ Outcome data } \\
\hline Ventilation time $(\mathrm{h}) *$ & $88.3(42.5-163.4)$ & $69.8(25.3-179.3)$ & $107.5(78.0-152.2)$ & $91.5(32.6-163.1)$ \\
\hline VFD day 28 & $24(20-26)$ & $24(19-26)$ & $23(21-24)$ & $24(21-26)$ \\
\hline PICU mortality (\%) & 6.0 & 4.3 & 2.6 & 3.7 \\
\hline
\end{tabular}

\section{Bench model testing}

The median mechanical energy measured in the lung was significantly higher with VC (4.8 [2.7-8.2] than with $\mathrm{PC}$ ventilation $(2.3[1.2-3.4] \mathrm{mJ} / \mathrm{kg}, p<$ 0.001). We also found that the mechanical energy lost due to resistive properties of the respiratory system was significantly higher with VC (7.4 [4.712.4] than with PC $(3.8[1.6-7.2] \mathrm{mJ} / \mathrm{kg}, p<0.001)$. ETT size was significantly correlated with mechanical energy in the lung $\left(r_{s}-0.055, p<0.01\right)$ and mechanical energy lost due to resistive properties of the respiratory system $\left(r_{s}-0.050, p<0.01\right)$. Multivariate analysis showed that for VC but not PC, ETT size $(p<0.001)$ was independently associated with the percentage of MEventilator delivered to the lung, irrespective of compliance or resistance settings (Table 2).

\section{Discussion}

This is the first pediatric study investigating energy transmission during mechanical ventilation. We found that mechanical energy per breath correlated with underlying lung pathology and patient outcome. Bench testing showed that during PC ventilation, ETT size itself did not affect energy delivery to the lung. Our data provide support to further exploring the conceptual framework of energy transmission during $\mathrm{MV}$ in the pediatric setting.

Recurrent delivery of tidal energy inflicts VILI when stress and strain exceed the limits of tissue tolerance. Experimental work linked mechanical power $>12 \mathrm{~J} / \mathrm{min}$ to the development of VILI [18-21] and adverse outcome in clinical studies in adults [7, 8, 22]. To date, there are no pediatric studies that have examined such relationship. Although it is not clear which component 

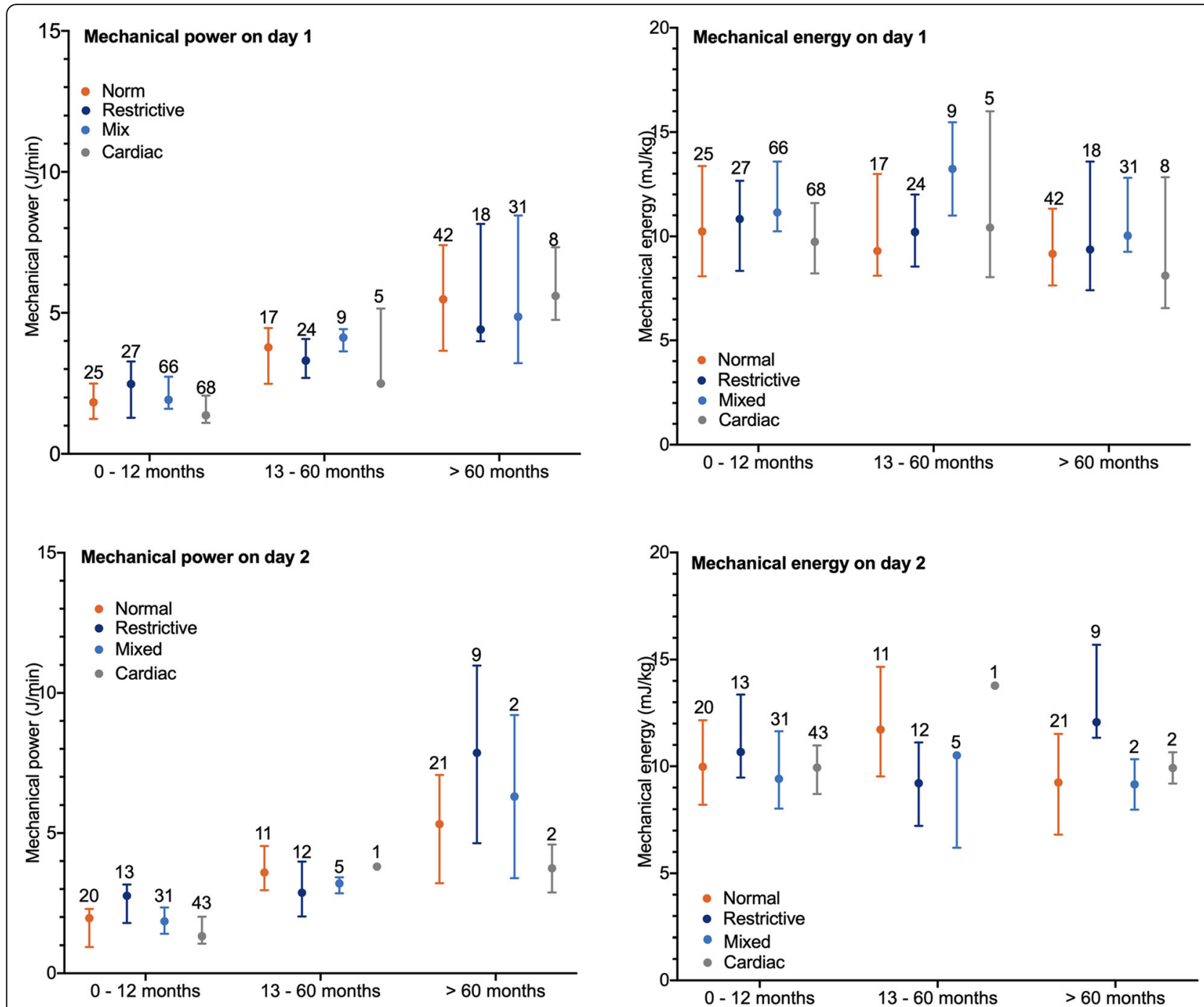

Fig. 1 Distribution of mechanical power of the respiratory system (MPrs) on day 1 (upper left panel) and day 2 (lower left panel) and the mechanical energy per breath [MErs] on day 1 (upper right panel) and day 2 (lower right panel) stratified by Pediatric Mechanical Ventilation Consensus Conference (PEMVECC) defined type of respiratory system mechanics. Data are depicted as median (25-75 interquartile range). Absolute values above lines represent number of patients per PEMVECC type

of mechanical power contributes the strongest to lung damage, none of these components have been extensively studied in mechanically ventilated children and the relationship between mechanical ventilation and VILI in children remains unclear [2]. In fact, high Vt has been linked with better outcome in observational studies of children with acute lung injury, making it impossible to identify a specific Vt threshold to be associated with adverse outcomes [23-25]. Driving pressure has not been studied in children so far except for two observational studies reporting an association between a surrogate driving pressure (i.e., pressure gradient calculated by subtracting PEEP from the PIP measured under dynamic flow conditions) [26, 27].
Our study shows indicates that assessing the mechanical energy per breath seems appropriate when studying the effects of energy transmission on patient outcome instead of using the proposed formula for MPrs. Not only did we find values for MPrs far below previously published injurious thresholds in adults, we also found that there was no correlation with underlying pathology based on the PEMVECC criteria $[5,18]$. In fact, we found the highest values for MPrs among patients with no lung pathology which may be perceived as counterintuitive. A high tidal strain is a prerequisite for poor tissue damage, underscoring the injurious role of high Vt $[18,20]$. We propose that our observations may largely be caused by the age-dependency 
Table 2 Results from multivariate linear regression analysis from bench model testing data examining the independent contribution of categorized endotracheal tube (ETT) size $(0$ [ETT $3 \mathrm{~mm}$ ] to 5 [ETT $8 \mathrm{~mm}$ ]), categorized compliance (1 [normal] to 5 [severely low]), categorized resistance (1 [no resistance] to 3 [high]), categorized tidal volume (in $\mathrm{mL} / \mathrm{kg}$ ) for VC ventilation or pressure above PEEP for PC ventilation, and categorized inspiratory time (1 [- 20\% compared to age-appropriate] to 3 [+ 20\% compared to ageappropriate]) to the percentage of mechanical energy generated by the ventilator (calculated by $\left[\left(0.098 \times\left(\mathrm{Vt} \times \mathrm{kg}^{-1}\right) \times(\mathrm{PIP}-[(\mathrm{Pplat}\right.\right.$ - PEEP)/2])] with ventilator parameters measured at the $Y$ - piece) that is delivered to the lungs (measured by integrating the dynamic pressure - volume curve in the test lung)

\begin{tabular}{|c|c|c|c|}
\hline & $\beta$ & $95 \% \mathrm{Cl}$ & $P$ value \\
\hline \multicolumn{4}{|c|}{ A: Percentage of energy dissipated to the lung during VC ventilation } \\
\hline ETT size $(\mathrm{mm})$ & -1.391 & $-1.908 ;-0.0874$ & $<0.001$ \\
\hline $\mathrm{Vt}(\mathrm{mL} / \mathrm{kg})$ & 3.294 & $2.592 ; 3.997$ & $<0.001$ \\
\hline Compliance $\left(\mathrm{mL} / \mathrm{cmH}_{2} \mathrm{O} / \mathrm{kg}\right)$ & 13.326 & $12.931 ; 13.720$ & $<0.001$ \\
\hline Resistance & -8.061 & $-8.722 ;-7.401$ & $<0.001$ \\
\hline Inspiratory time (s) & 2.754 & $2.078 ; 3.430$ & $<0.001$ \\
\hline Inspiratory flow (L/min) & -0.041 & $-0.092 ; 0.009$ & 0.110 \\
\hline \multicolumn{4}{|c|}{ B: Percentage of energy dissipated to the lung during PC ventilation } \\
\hline ETT size $(\mathrm{mm})$ & 0.090 & $-0.299 ; 0.478$ & 0.650 \\
\hline Pressure above PEEP $\left(\mathrm{cmH}_{2} \mathrm{O}\right)$ & 0.602 & $0.444 ; 0.761$ & $<0.001$ \\
\hline Compliance $\left(\mathrm{mL} / \mathrm{cmH}_{2} \mathrm{O} / \mathrm{kg}\right)$ & 11.130 & $10.662 ; 11.598$ & $<0.001$ \\
\hline Resistance & -10.206 & $-11.000 ;-9.413$ & $<0.001$ \\
\hline Inspiratory time (s) & 4.322 & $3.528-5.115$ & $<0.001$ \\
\hline
\end{tabular}

of Vt and RR. From a developmental perspective, the older the child becomes, the larger the Vt gets and the lower the RR is, indicating that higher values of MPrs are automatically found in older children and thus making comparisons across the entire pediatric spectrum impossible. Furthermore, it could be surmised that this is also due to differences in lung size. When normalized to height instead of bodyweight, younger children have a relatively larger lung surface area than adults [2]. However, the actual delivered $\mathrm{Vt}$ in relation to the amount of inflatable lung volume will then be lower when still normalized to bodyweight leading to a lower lung strain compared with adults [28]. Aside from this, PC is the predominant ventilatory mode in pediatrics. Raw is not constant in PC because of the decelerative flow pattern; thus, (Ppeak - Pplat)/Flow cannot function as a proxy for Raw and Vt/Tinsp not for flow [29]. We overcame this applying an inspiratory hold to generate Pplat and found that the energy transmitted to the lung remained lower during $\mathrm{PC}$ than during $\mathrm{VC}$ ventilation. One obvious explanation would be the significantly lower delivered Vt during PC when setting an inspiratory pressure. Interestingly, multivariate testing showed that ETT size was not independently associated with the percentage of energy that was transmitted to the lung during PC ventilation, further supporting the use of mechanical energy rather than mechanical power in the pediatric setting where PC ventilation is very common. Nonetheless, although mechanical energy per breath showed an observed a better relationship with lung pathology based on the PEMVECC criteria, injurious thresholds obviously need to be identified in future studies.

Our study has several limitations. First, our clinical study was designed a single-center study that may limit the generalizability of our findings, although our unit is comparable to most large units globally. In addition, the clinical relevance of mechanical has only been studied in ARDS, but our cohort included only a small group of PARDS patients. Second, although lung-protective ventilation is guided by a unit-specific clinical algorithm guiding pressure and Vt setting, setting the level of PEEP was not dictated by the ARDS Network grid. Recently, it has been shown that not adhering to the grid was associated with increased mortality, although these findings need to be universally confirmed [30]. Third, although we showed that MErs on day 1 or day 2 was independently associated with total ventilation time after adjusting for age, disease severity, and PEMVECC lung pathology type, this does not mean that there is a causative relationship between MErs and patient outcome since other confounders may not have been picked up. For example, our unit has a low threshold for using HFOV as an alternative mode of ventilation which may impact total ventilation time [31,32]. Also, there was no use of extubation readiness testing, thereby affecting total ventilation time [33]. Importantly, it remains to be studied if mechanical energy may be interpreted as a 
driver of the outcome. Fourth, our bench test represented a simplification of the actual clinical situation because by design, a bench only represents homogeneous lung conditions.

\section{Conclusions}

Compared with mechanical power, mechanical energy per breath correlates better with underlying lung pathology and patient outcome in mechanically ventilated children. Delivery of the generated energy was not dependent on endotracheal tube size during pressurecontrolled ventilation. Future studies are needed to identify injurious thresholds of mechanical energy.

\section{Supplementary information}

Supplementary information accompanies this paper at https://doi.org/10. 1186/s13054-020-03313-7.

Additional file 1. Electronic Supplemental Material To Energy transmission in mechanically ventilated children: a translational study. Methodology of the bench test.

\section{Abbreviations}

ARDS: Acute respiratory distress syndrome; Crs: Compliance of the respiratory system; DP: Driving pressure; ETT: Endotracheal tube; MElung: Mechanical energy measured in the test lung; MErs: Mechanical energy of the respiratory system; MEventilator: Mechanical energy measured in the ventilator; MPrs : Mechanical power of the respiratory system; MV: Mechanical ventilation; Ol: Oxygenation index; OSI: Oxygen saturation index; PALICC: Pediatric Acute Lung Injury Consensus Collaborative; PARDS: Pediatric acute respiratory distress syndrome; PC: Pressure control; PEEP: Positive end-expiratory pressure; PICU: Pediatric intensive care unit; PIP: Peak inspiratory pressure; Pplat: Plateau pressure; PRISM: Pediatric risk of mortality; RR: Respiratory rate; Rrs: Resistance of the respiratory system; Tinsp: Inspiratory time; VC: Volume control; VILI: Ventilator-induced lung injury; Vt: Tidal volume

\section{Acknowledgements}

The authors would like to thank Sandra K. Dijkstra, RN, for assisting in the clinical data collection.

\section{Authors' contributions}

MK designed and supervised the study. SI performed all bench experiments. PVS and JVD acquired all clinical data. All authors performed data analysis and interpretation. JB assisted in the statistical analyses. MK, SI, and RB wrote the manuscript. All authors contributed to the manuscript draft and revision. The author(s) read and approved the final manuscript.

\section{Funding}

None

\section{Availability of data and materials}

The datasets used and/or analyzed during the current study are available from the corresponding author on reasonable request.

\section{Ethics approval and consent to participate}

The Institutional Review Board of the UMC Groningen approved the study and waived the need for informed consent.

\section{Consent for publication}

Not applicable

\section{Competing interests}

MK serves as a consultant for Vyaire. The other authors declare that they have no competing interests.

\section{Author details}

'Division of Paediatric Critical Care Medicine, Department of Paediatrics, Beatrix Children's Hospital, University Medical Center Groningen, The University of Groningen, Internal Postal Code CA 80, P.O. Box 30.001, 9700, $\mathrm{RB}$, Groningen, the Netherlands. ${ }^{2} \mathrm{Critical}$ Care, Anesthesia, Peri-operative Medicine \& Emergency Medicine (CAPE), The University of Groningen, Groningen, the Netherlands. ${ }^{3}$ Pediatric Intensive Care Unit, University Hospital Heraklion, University of Crete, Crete, Greece. ${ }^{4}$ Department of Epidemiology, University Medical Center Groningen, The University of Groningen, Groningen, the Netherlands. ${ }^{5}$ Pediatric Intensive Care Unit, Emma Children's Hospital, Amsterdam UMC, Amsterdam, the Netherlands.

Received: 17 June 2020 Accepted: 28 September 2020

Published online: 07 October 2020

References

1. Slutsky AS, Ranieri VM. Ventilator-induced lung injury. N Engl J Med. 2013; 369:2126-36.

2. Kneyber MC, Zhang $H$, Slutsky AS. Ventilator-induced lung injury. Similarity and differences between children and adults. Am J Respir Crit Care Med. 2014;190(3):258-65.

3. Gattinoni L, Marini JJ, Collino F, Maiolo G, Rapetti F, Tonetti T, Vasques F, Quintel M. The future of mechanical ventilation: lessons from the present and the past. Crit Care. 2017:21(1):183.

4. Marini JJ, Rocco PRM, Gattinoni L. Static and dynamic contributors to ventilator-induced lung injury in clinical practice. Pressure, energy, and power. Am J Respir Crit Care Med. 2020;201(7):767-74.

5. Gattinoni L, Tonetti T, Cressoni M, Cadringher P, Herrmann P, Moerer $\mathrm{O}$, Protti A, Gotti M, Chiurazzi C, Carlesso E, et al. Ventilator-related causes of lung injury: the mechanical power. Intensive Care Med. 2016;42(10):1567-75.

6. Serpa Neto A, Deliberato RO, Johnson AEW, Bos LD, Amorim P, Pereira SM, Cazati DC, Cordioli RL, Correa TD, Pollard TJ, et al. Mechanical power of ventilation is associated with mortality in critically ill patients: an analysis of patients in two observational cohorts. Intensive Care Med. 2018;44(11): 1914-22.

7. Parhar KKS, Zjadewicz K, Soo A, Sutton A, Zjadewicz M, Doig L, Lam C, Ferland A, Niven DJ, Fiest KM, et al. Epidemiology, mechanical power, and 3-year outcomes in acute respiratory distress syndrome patients using standardized screening. An observational cohort study. Ann Am Thorac Soc. 2019;16(10):1263-72.

8. Zhang Z, Zheng B, Liu N, Ge H, Hong Y. Mechanical power normalized to predicted body weight as a predictor of mortality in patients with acute respiratory distress syndrome. Intensive Care Med. 2019;45(6):856-64.

9. Becher T, van der Staay M, Schadler D, Frerichs I, Weiler N. Calculation of mechanical power for pressure-controlled ventilation. Intensive Care Med. 2019:45(9):1321-3.

10. Santschi M, Jouvet P, Leclerc F, Gauvin F, Newth CJ, Carroll CL, Flori H, Tasker RC, Rimensberger PC, Randolph AG, et al. Acute lung injury in children: therapeutic practice and feasibility of international clinical trials. Pediatr Crit Care Med. 2010:11(6):681-9.

11. Santschi $M$, Randolph $A G$, Rimensberger PC, Jouvet $P$, Pediatric Acute Lung Injury Mechanical Ventilation Investigators tPALI, Sepsis Investigators $N$, the European Society of $\mathrm{P}$, Neonatal Intensive C: Mechanical ventilation strategies in children with acute lung injury: a survey on stated practice pattern*. Pediatr Crit Care Med 2013, 14(7):e332-e337.

12. Hentschel R, Buntzel J, Guttmann J, Schumann S. Endotracheal tube resistance and inertance in a model of mechanical ventilation of newborns and small infants-the impact of ventilator settings on tracheal pressure swings. Physiol Meas. 2011:32(9):1439-51.

13. Kneyber MCJ, de Luca D, Calderini E, Jarreau PH, Javouhey E, Lopez-Herce J, Hammer J, Macrae D, Markhorst DG, Medina A, et al. Recommendations for mechanical ventilation of critically ill children from the Paediatric Mechanical Ventilation Consensus Conference (PEMVECC). Intensive Care Med. 2017:43(12):1764-80

14. Pollack MM, Patel KM, Ruttimann UE. PRISM III: an updated Pediatric Risk of Mortality score. Crit Care Med. 1996:24(5):743-52.

15. Khemani RG, Smith LS, Zimmerman JJ, Erickson S, Pediatric Acute Lung Injury Consensus Conference G: Pediatric acute respiratory distress syndrome: definition, incidence, and epidemiology: proceedings from the pediatric acute lung injury consensus conference. Pediatr Crit Care Med 2015, $16(5$ Suppl 1):S23-S40 
16. Yehya N, Harhay MO, Curley MAQ, Schoenfeld DA, Reeder RW. Reappraisal of ventilator-free days in critical care research. Am J Respir Crit Care Med. 2019;200(7):828-36.

17. Bakoyannis $G$, Touloumi $G$. Practical methods for competing risks data: a review. Stat Methods Med Res. 2012;21(3):257-72.

18. Moraes L, Silva PL, Thompson A, Santos CL, Santos RS, Fernandes MVS, Morales MM, Martins V, Capelozzi VL, de Abreu MG, et al. Impact of different tidal volume levels at low mechanical power on ventilator-induced lung injury in rats. Front Physiol. 2018;9:318.

19. Cressoni M, Gotti M, Chiurazzi C, Massari D, Algieri I, Amini M, Cammaroto A, Brioni M, Montaruli C, Nikolla K, et al. Mechanical power and development of ventilator-induced lung injury. Anesthesiology. 2016;124(5): $1100-8$.

20. Santos RS, Maia LA, Oliveira MV, Santos CL, Moraes L, Pinto EF, Samary CDS, Machado JA, Carvalho AC, Fernandes MVS, et al. Biologic impact of mechanical power at high and low tidal volumes in experimental mild acute respiratory distress syndrome. Anesthesiology. 2018;128(6):1193-206.

21. Maia LA, Samary CS, Oliveira MV, Santos CL, Huhle R, Capelozzi VL, Morales MM, Schultz MJ, Abreu MG, Pelosi P, et al. Impact of different ventilation strategies on driving pressure, mechanical power, and biological markers during open abdominal surgery in rats. Anesth Analg. 2017;125(4):1364-74.

22. Serpa Neto A, Schmidt M, Azevedo LC, Bein T, Brochard L, Beutel G, Combes A, Costa EL, Hodgson C, Lindskov C, et al. Associations between ventilator settings during extracorporeal membrane oxygenation for refractory hypoxemia and outcome in patients with acute respiratory distress syndrome: a pooled individual patient data analysis: mechanical ventilation during ECMO. Intensive Care Med. 2016:42(11):1672-84.

23. Erickson S, Schibler A, Numa A, Nuthall G, Yung M, Pascoe E, Wilkins B. Acute lung injury in pediatric intensive care in Australia and New Zealand: a prospective, multicenter, observational study. Pediatr Crit Care Med. 2007; 8(4):317-23.

24. Khemani RG, Conti D, Alonzo TA, Bart RD 3rd, Newth CJ. Effect of tidal volume in children with acute hypoxemic respiratory failure. Intensive Care Med. 2009;35(8):1428-37.

25. de Jager P, Burgerhof JG, van Heerde M, Albers MJ, Markhorst DG, Kneyber MC. Tidal volume and mortality in mechanically ventilated children: a systematic review and meta-analysis of observational studies*. Crit Care Med. 2014;42(12):2461-72.

26. Yehya $\mathrm{N}$, Thomas NJ. Disassociating lung mechanics and oxygenation in pediatric acute respiratory distress syndrome. Crit Care Med. 2017;45(7): 1232-9.

27. Panico FF, Troster EJ, Oliveira CS, Faria A, Lucena M, Joao PR, Saad ED, Foronda FA, Delgado AF, de Carvalho WB. Risk factors for mortality and outcomes in pediatric acute lung injury/acute respiratory distress syndrome. Pediatr Crit Care Med. 2015;16(7):e194-200.

28. Ward SL, Quinn CM, Steurer MA, Liu KD, Flori HR, Matthay MA. Variability in pediatric ideal body weight calculation: implications for lung-protective mechanical ventilation strategies in pediatric acute respiratory distress syndrome. Pediatr Crit Care Med. 2018;19(12):e643-52.

29. Zhao Z, Frerichs I, He H, Long Y, Moller K, Serpa Neto A, Schultz MJ. The calculation of mechanical power is not suitable for intra-patient monitoring under pressure-controlled ventilation. Intensive Care Med. 2019;45(5):74950 .

30. Khemani RG, Parvathaneni K, Yehya N, Bhalla AK, Thomas NJ, Newth CJL. PEEP lower than the ARDS network protocol is associated with higher pediatric ARDS mortality. Am J Respir Crit Care Med. 2018;198(1):77-89.

31. Bateman ST, Borasino S, Asaro LA, Cheifetz IM, Diane S, Wypij D, Curley MA, Investigators RS. Early high-frequency oscillatory ventilation in pediatric acute respiratory failure. A propensity score analysis. Am J Respir Crit Care Med. 2016;193(5):495-503.

32. Kneyber MC, Markhorst DG. Do we really know how to use high-frequency oscillatory ventilation in critically ill children? Am J Respir Crit Care Med. 2016;193(9):1067-8.

33. Foronda FK, Troster EJ, Farias JA, Barbas CS, Ferraro AA, Faria LS, Bousso A, Panico FF, Delgado AF. The impact of daily evaluation and spontaneous breathing test on the duration of pediatric mechanical ventilation: a randomized controlled trial. Crit Care Med. 2011;39(11):2526-33.

\section{Publisher's Note}

Springer Nature remains neutral with regard to jurisdictional claims in published maps and institutional affiliations.

Ready to submit your research? Choose BMC and benefit from:

- fast, convenient online submission

- thorough peer review by experienced researchers in your field

- rapid publication on acceptance

- support for research data, including large and complex data types

- gold Open Access which fosters wider collaboration and increased citations

- maximum visibility for your research: over $100 \mathrm{M}$ website views per year

At BMC, research is always in progress.

Learn more biomedcentral.com/submissions 